Research Article

\title{
Prefabricated Urban Underground Utility Tunnels: A Case Study on Mechanical Behaviour with Strain Monitoring and Numerical Simulation
}

\author{
Yonggang Xiao $\mathbb{D}^{1,2}$ Jubing Zhang $\mathbb{D}^{1},{ }^{1}$ Jie Cao $\mathbb{D}^{2},{ }^{2}$ and Changhong Li $\mathbb{D}^{1}$ \\ ${ }^{1}$ Beijing Key Laboratory of Urban Underground Space Engineering, University of Science and Technology Beijing, \\ Beijing 100083, China \\ ${ }^{2}$ Department of Architecture and Civil Engineering, Chengde Petroleum College, Chengde 067000, China
}

Correspondence should be addressed to Jubing Zhang; zjb_www@163.com and Jie Cao; caojieshiyou@163.com

Received 24 January 2021; Revised 18 February 2021; Accepted 3 March 2021; Published 11 March 2021

Academic Editor: Jianwei Tian

Copyright ( $\odot 2021$ Yonggang Xiao et al. This is an open access article distributed under the Creative Commons Attribution License, which permits unrestricted use, distribution, and reproduction in any medium, provided the original work is properly cited.

The prefabricated urban utility tunnels (UUTs) have many advantages such as short construction period, low cost, high quality, and small land occupation. However, there is still a lack of in-depth analysis of the mechanical performance of the prefabricated urban utility tunnel (UUT) structure with bolted connections under different working conditions. In this paper, the force performance of a prefabricated UUT in Tongzhou District, Beijing, was studied under different working conditions using two methods: field monitoring and numerical simulation. The multichannel strain monitor was used for monitoring, and the internal wall concrete and bolt strain change data under the two conditions of installation and backfill were obtained. Combined with the construction process of the UUTs, a three-dimensional numerical model was established by COMSOL, where the build-in bolt assembly was used to simulate the longitudinal connection of the tunnel. The simulation results were compared with the measured data to verify the rationality of the computational model. The simulation results showed that the concrete and bolts on the inner wall of the tunnel work well under the two conditions of installation and backfilling; The deformation of the top plate of the prefabricated tunnel was approximately parabolic, with the largest vertical displacement $(0.37 \mathrm{~mm})$ in the middle and the most sensitive to the vertical load in the central part of the roof. The central portion of the side wall had the largest displacement $(0.17 \mathrm{~mm})$ in the inner concave. The tensile stress of bolt 3 increased the most $(30.75 \mathrm{MPa})$ but was still much smaller than the yield strength of the bolt. The concrete and bolts of the UUT were found to work well through force analysis under operating conditions. In conclusion, analysis of structural forces and deformation failure modes will help design engineers understand the basic mechanisms and select the appropriate UUT structure.

\section{Introduction}

The urban utility tunnels can avoid the interference of urban traffic networks, reduce the public space occupied by municipal pipelines, and make the underground space very neat, which is conducive to maintenance, renewal, and expansion of new pipeline facilities. Therefore, they have become an optimal solution for future development $[1,2]$. Traditional municipal pipelines are very crowded underground and cannot cope with modern urbanization. China's urban public utility tunnels are experiencing drastic growth, creating huge market opportunities, and facing many engineering problems that need to be solved [3]. In order to achieve sustainable development, urban utility tunnels are used to solve these problems [4]. UUTs are building and ancillary facilities built on the underground of the city to accommodate two or more types of urban engineering pipelines [5]. There are two main UUTs construction methods: the cast-in-place construction method and the prefabrication construction method. Compared with castin-place construction technology, prefabricated UUTs have many advantages such as shortening the construction period, reducing land occupation, saving cost, improving quality, and less environmental pollution. The structural 
section forms commonly used in prefabrication construction methods are circular and rectangular. Because the circular section space utilization rate is not as good as the rectangular section, the rectangular cross section has gradually been favoured by the design unit in many UUTs projects.

However, the force characteristics of the prefabricated UUTs are different from those of the surface structures. Different buried depths, adjacent structures, and ground loads lead to the complex performance of the tunnel, and these factors have a great influence on the project cost and the design of the UUTs. The variation of the buried depth of the prefabricated UUTs can be simulated by changing the load applied to the top and side walls. The structural deformation, stress distribution, and failure form of the prefabricated UUT under different buried depths show regular changes when the uniform pressure is applied to the roof of the tunnel, and the lateral Earth pressure is applied to the side wall plate [6]. Under the action of high-intensity seismic loads, the UUT undergoes large deformation and acceleration, and its response is greater than that of the surrounding soil [7]. Garg and Abolmaali [8, 9] used strain gauges and a high-resolution laser deflection sensor to measure the load and deflection of the precast concrete box girder and established a finite element model of the box girder to analyze the load-deflection curve. By comparing with the test results, it showed that both the numerical simulation results and the test results had a good correlation. Based on the UUTs project of the Shanghai World Expo Park, Xue et al. [10-12] studied the mechanical properties of prefabricated tube joint connected by prestressed steel bar through fullscale model tests. The stress process of tube joint using prestressed steel bar is divided into three stages: pressure reduction, yielding, and ultimate failure. The flexural capacity of the joint is 2.1 times the bending moment of the design. Du et al. [13] studied the seismic performance of prefabricated joints through low-cycle loading tests and numerical simulations of full-scale models taking the prefabricated bottom node of a subway station as the research background. A simplified treatment method for grouting sleeves was proposed and the numerical analysis results were in good agreement with the experimental results.

Although the prefabricated UUT has been used in construction, it has not been widely adopted. The reason is mainly due to the uncertainty of the prefabricated UUTs in many aspects. So, many engineering projects are still built using test sections. Prefabricated UUTs currently have two main joining methods: prestressed connections and bolted connections. The prefabricated prestressed tube connection has its advantages, but the disadvantages are also obvious. Because the posttensioning method is mainly used, the prefabricated prestressed UUTs construction process is more complicated than bolted connection construction. The stress state and corrosion condition of the inner force bar of the pipe are not easy to observe or replace. The friction loss in the pipe is large, and the stress loss cannot be compensated. Effectively solving these problems is dependent on effectively studying the prefabricated UTT. However, there is still a lack of in-depth analysis of the prefabricated UUTs structure and the performance of the tube joints under complex conditions. During the construction and operation period, prefabricated UUTs are subject to Earth pressure, vehicle dynamic loads, and even seismic loads. After being subjected to these loads, the form of force and damage of the tube's concrete and connecting bolts is not fully understood.

In this paper, the strain on the concrete and bolts of the precast UUTs was monitored using strain gauges. And with the finite element analysis software COMSOL, the longitudinal connection of the UUTs was simulated using the software's built-in bolt assembly. The mechanical behavior of prefabricated UUTs was simulated under different working conditions. And compared with the monitoring data, the area where the structure had hidden dangers and the possible failure mode were proposed. The analysis of structural forces and deformation failure modes will help design engineers understand the basic mechanisms and select the appropriate UUT structure.

\section{Materials and Methods}

2.1. The UUTs under Study. In this paper, the prefabricated UUTs of a cultural tourism area in Tongzhou District of Beijing were taken as the research background. The UUTs studied had a single-chamber structure that accommodates $10 \mathrm{kV}$ cables, water injection pipes, reclaimed water pipes, telecommunications pipes, and reserved pipe positions. The prefabricated UUT had an external dimension of $3.1 \mathrm{~m} \times 3.5 \mathrm{~m}$, an internal dimension of $2.5 \mathrm{~m} \times 2.8 \mathrm{~m}$, and a single component weight of $20 \mathrm{t}$. The thickness of the backfill above the top of the UUT was $5.15 \mathrm{~m} \sim 7.50 \mathrm{~m}$, designed as a tunnel that can pass through, as shown in Figures 1(a) and 1(b). The flat seam was used for splicing between adjacent tube joints. The longitudinal direction of the members was connected by curved bolts. Eight arc-shaped bolts were arranged on each joint surface. The diameter of the curved bolts was $27 \mathrm{~mm}$ and the strength class is 8.8 . The hexagonal nut had an inner diameter of $27 \mathrm{~mm}$, outer diameter of $47.3 \mathrm{~mm}$, and a thickness of $23.8 \mathrm{~mm}$. A steel washer was placed under each nut with an inner diameter of $28 \mathrm{~mm}$, an outer diameter of $60 \mathrm{~mm}$, and a thickness of $10 \mathrm{~mm}$, as shown in Figure 1(c).

2.2. Monitoring Point Scheme. The construction process of the prefabricated UUT of this project is roughly divided into three construction stages in order.

Stage 1: installation, including the lifting of the prefabricated UUT in place, alignment, pretightening force, fastening bolts, and so forth

Stage 2: backfilling, the foundation pit soil is backfilled to the design elevation

Stage 3: operation, paving the road and the vehicle running on it

Three continuous tube joints were selected for construction monitoring. The monitoring items include the internal surface strain of the concrete, the concrete strain behind the bolt, and the axial strain of the bolt. Strain measurements were 


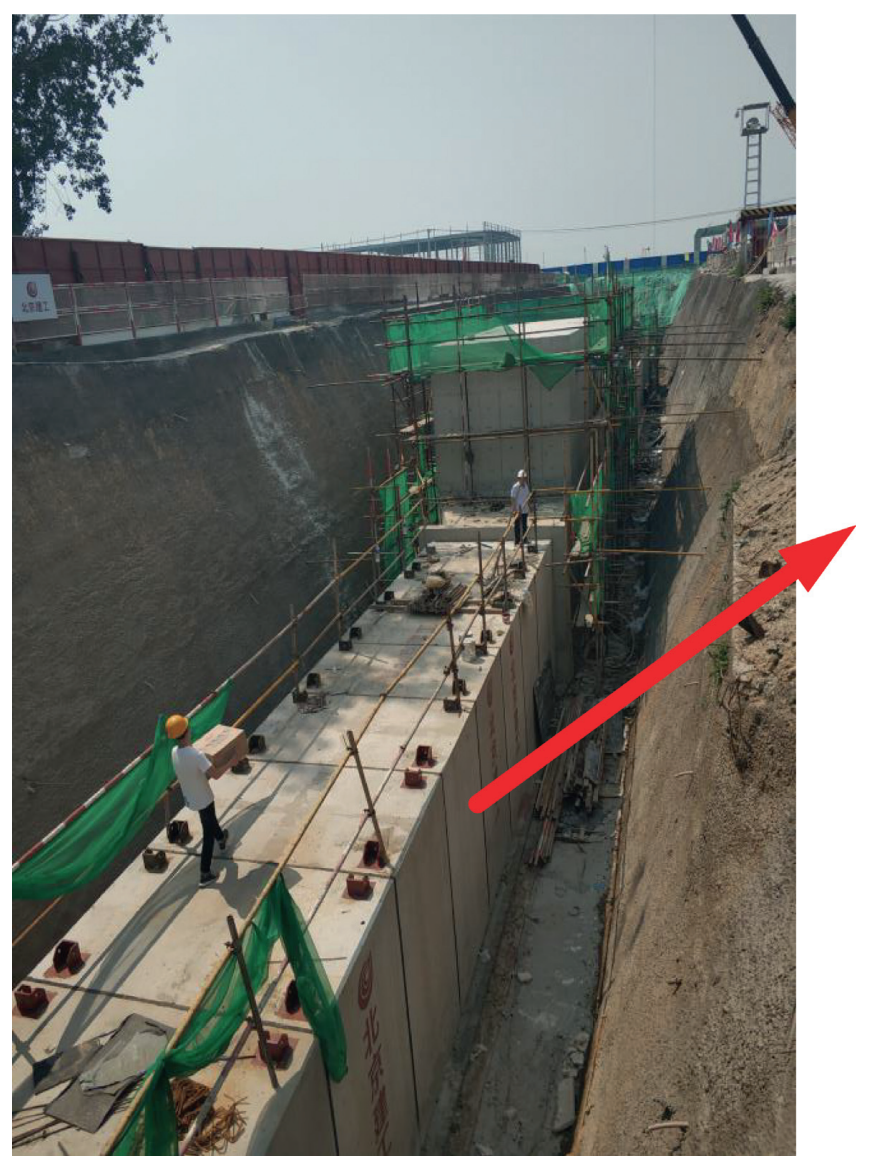

(a)

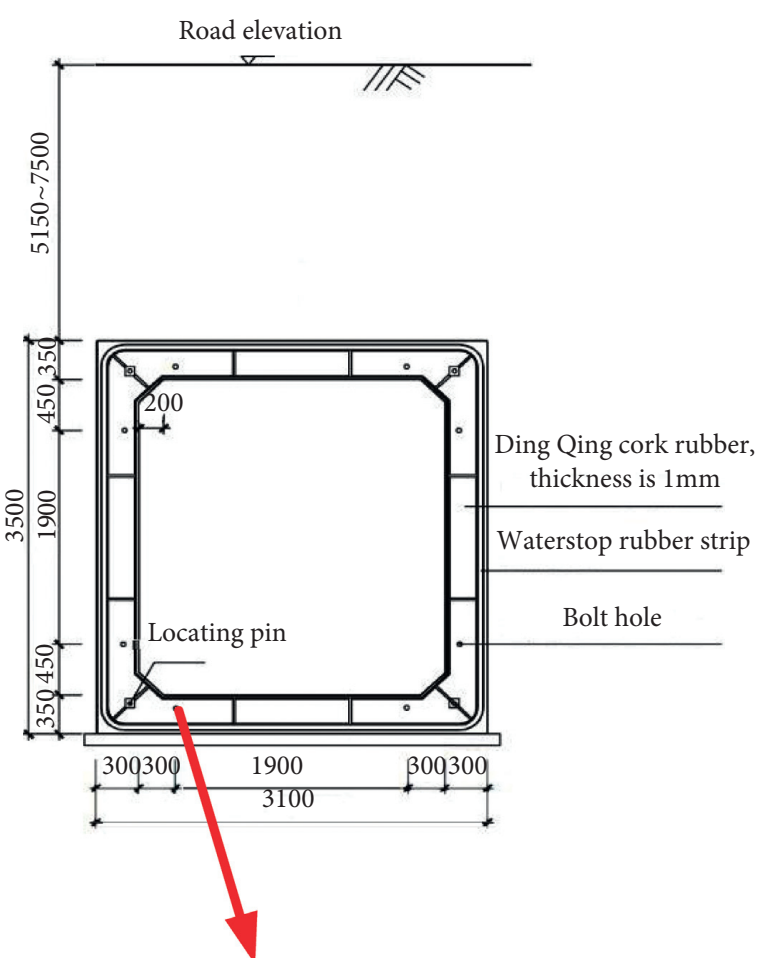

(b)

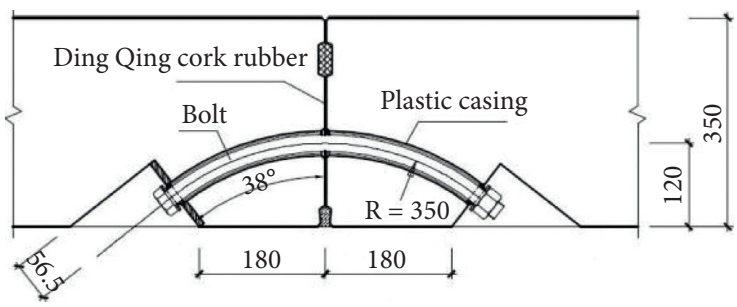

(c)

Figure 1: (a) Photography prefabricated UUT in Tongzhou District, Beijing. (b) Standard section. (c) Schematic diagram of the joint interface.

performed using the TST3830 dynamic and static signal test and analysis system, which had a maximum sampling frequency of $100 \mathrm{~Hz}$. Two controllers were used for this monitoring, each controlling up to 8 acquisition modules, each measuring 16 channels (i.e., a total of 256 channels). The location and number of sensors depend on the cross-sectional form of the member and its force characteristics. The strain measurement points are arranged differently for different cross-sectional geometries of members. According to the cross-sectional geometry and force characteristics of the member, for biaxially symmetrical cross-sectional members, the middle part of the member may be deflected, and two strain sensors can be arranged symmetrically at the maximum deflection of the member. The monitoring points were arranged as shown in Figures 2(a) and 2(b).

$G(m, n)$ represents the measuring point of the inner surface in the middle of the UUT section. The $1^{\text {st }}$ number after $G$ or $(m)$ represents the sequence of the UUT section; the $2^{\text {nd }}(n)$ number represents the monitoring point number. For example, G12 represents the $2^{\text {nd }}$ measuring point of the $1^{\text {st }}$ UUT section when splicing. The measuring point on the left wall is taken as the $1^{\text {st }}$ measuring point, with measuring points numbered in a clockwise direction across the splicing direction (Figure 2(b)). Therefore, the top surface is the $2^{\text {nd }}$ measuring point, and the right side wall is the $3^{\text {rd }}$ measuring point. $\mathrm{MH}(x, y, z)$ stands for the concrete measuring point behind the groove of the anchor bolt. The first number after $\mathrm{MH}(x)$ represents the number of the UUT section, and the second number $(y)$ which is equal to 1 or 2 indicates the sequence of the splicing pipeline. 1 indicates the measurement point of the pipe that is joined first, and 2 indicates the measurement point of the postjoint. The last digit behind $\mathrm{MH}$ represents the point number. For example, MH111 represents the first measurement point before the first tunnel section of the splicing (Figure 2(a)). Three-direction strain flowers were attached to each concrete measuring point (Figure 2(c)); $X$ was defined as a horizontal measuring point, $Y$ was a vertical measuring point, and $Z$ was a 45 -degree measuring point. $B(j, k)$ stands for the measuring point of the metal strain gauge on the bolt. The first number after $B$ represents the number of the tube joint, and the second number after $B$ represents the point number. For example, 


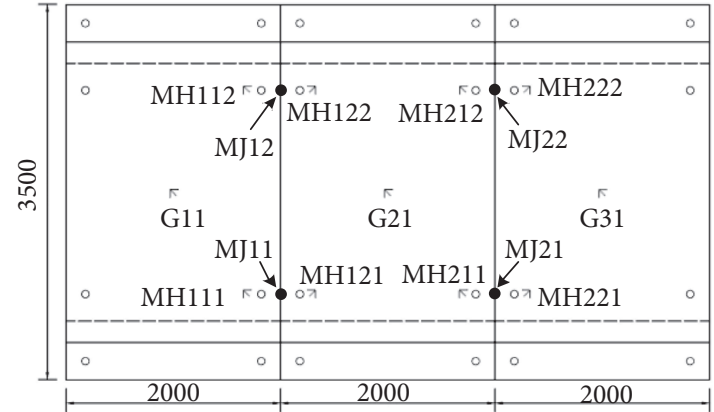

- Bolt hole position

- Axial strain measuring point of bolt

$\rtimes$ Strain measurement point of concrete

(a)
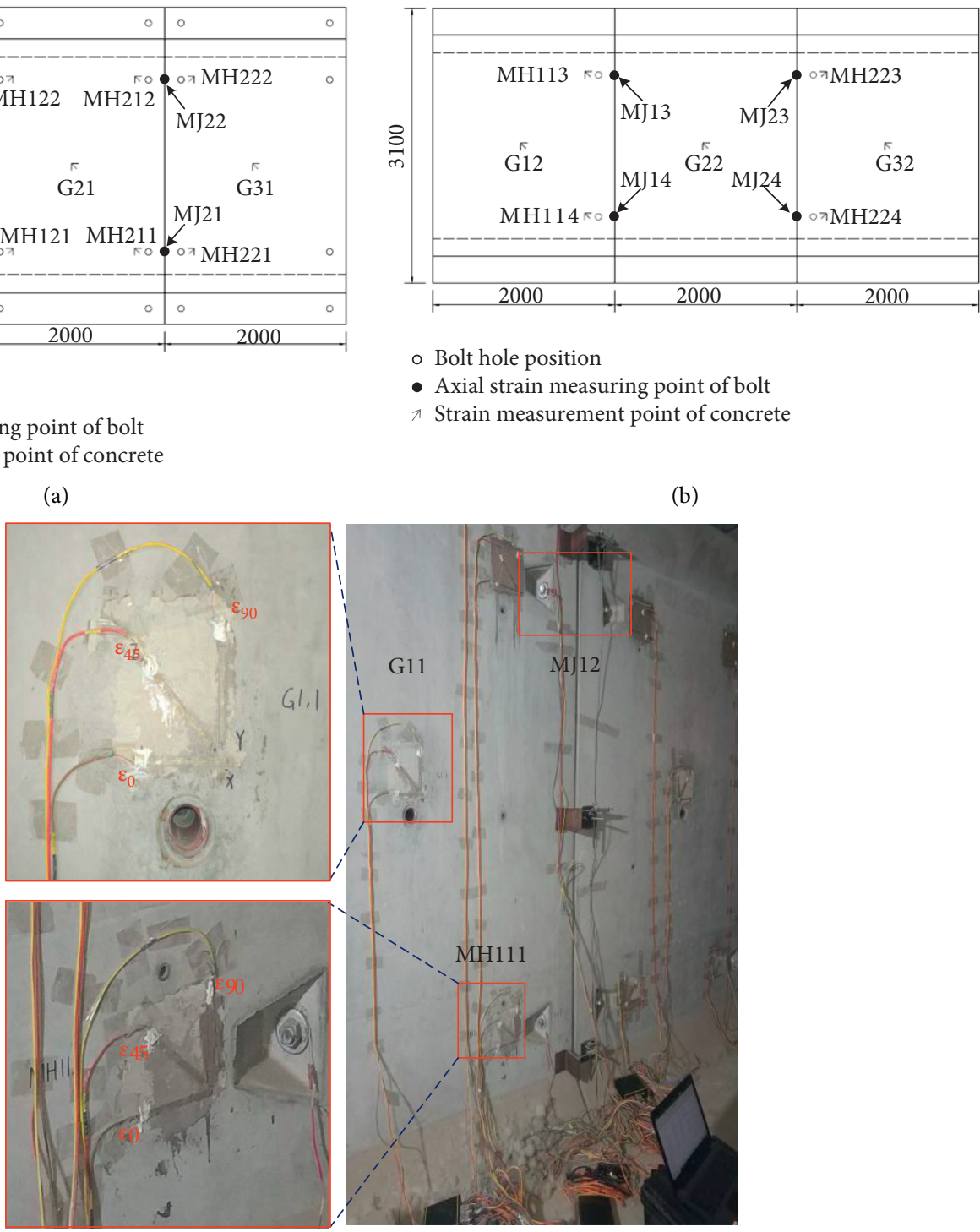

- Bolt hole position

- Axial strain measuring point of bolt

$\pi$ Strain measurement point of concrete

(b)

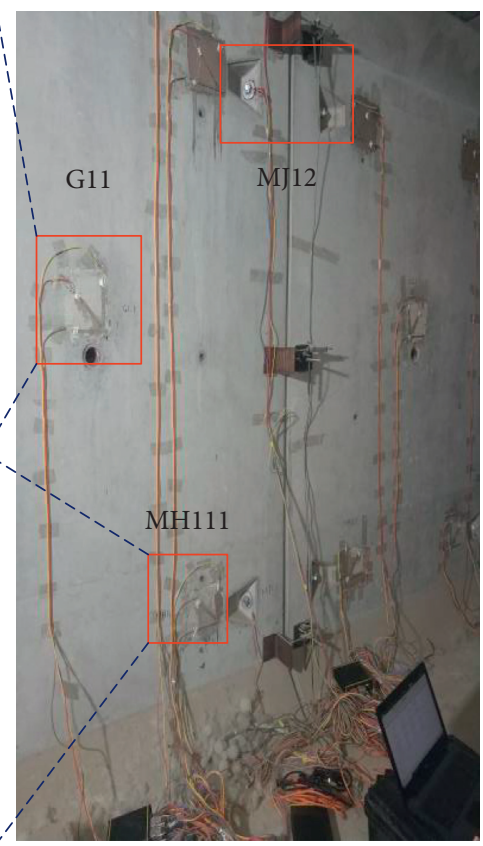

(c)

Figure 2: Monitoring point layout. (a) Side view of the measuring point inside the tunnel. (b) Top view of the measuring point inside the tunnel. (c) Strain flower in the UUT for monitoring interface.

the first measuring point of the first tube joint is represented by B11(Figure 2(a)), and so on. The condition of the strained flower inside the UUT is shown in Figure 2(c).

During the construction period, the data collection was carried out six times. Data collection is performed when the thickness of the backfill is $0 \mathrm{~m}, 2 \mathrm{~m}, 3.5 \mathrm{~m}, 6 \mathrm{~m}, 8.5 \mathrm{~m}, 11 \mathrm{~m}$. During the period, the two main construction processes of tube splicing and backfill construction were experienced. Through the monitoring, the strains in the $X, Y$, and $Z$ directions can be obtained, and the right angle strain flower was used. For comparison, the strains obtained in the three directions are converted into equivalent strains [14-17] using the following formula:

$$
\varepsilon_{e}=\frac{1}{1.3 \sqrt{2}} \sqrt{2.78 \varepsilon_{0}^{2}+2.78 \varepsilon_{90}^{2}-0.44 \varepsilon_{0} \varepsilon_{90}+1.5\left(\varepsilon_{0}-2 \varepsilon_{45}+\varepsilon_{90}\right)^{2}},
$$

where $\varepsilon_{e}$ is the equivalent strain, $\varepsilon_{0}$ is the strain measured in the $0^{\circ}$ direction, $\varepsilon_{90}$ is the strain measured in the $90^{\circ}$ direction, and $\varepsilon_{45}$ is the strain measured in the $45^{\circ}$ direction.

\subsection{Establishment of the Calculation Model and Verification.} Considering that the geometry of the tube and the load are symmetric along the central axis (Figure 3(a)), in order to reduce the number of model elements and the calculation time, symmetric boundaries were set at the symmetrical position, and the model only selected half of the tube for modelling (Figure 3(b)). A uniformly distributed load was applied to the ceiling of the tunnel, and the two side wall plates applied a uniformly varying linear lateral pressure, and a hinge support constraint was designed on both ends of the bottom plate, as shown in Figure 3(b). 


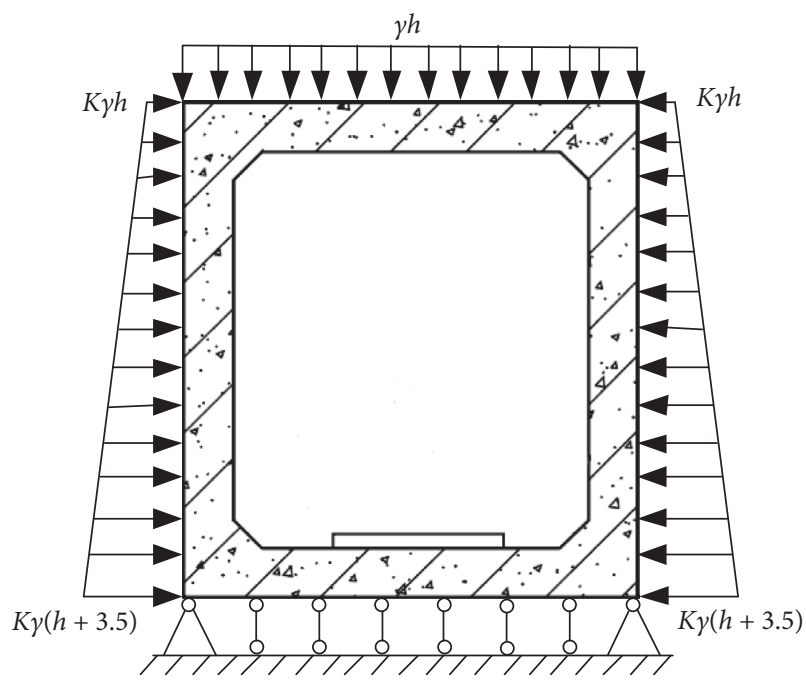

(a)

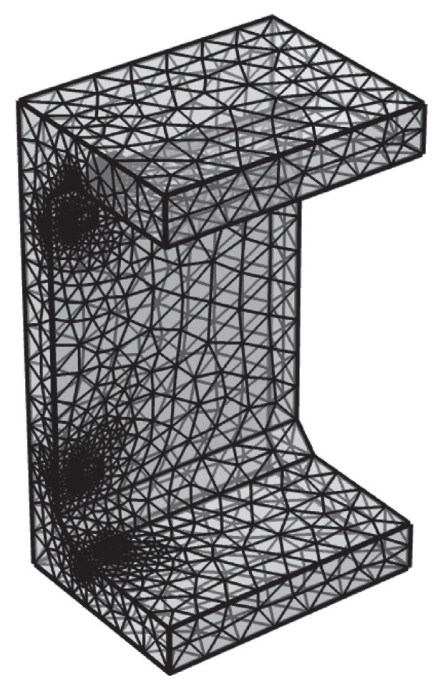

(b)

Figure 3: Numerical calculation model. (a) Load and constraint diagram. (b) Model meshing diagram.

\subsubsection{Basic Assumption}

(1) The bottom layer is relatively hard, and the base reaction force is linearly distributed

(2) Regardless of the interaction of soil and structure, the earth pressure under different burial depths is directly applied to the model

(3) Except for Earth pressure and structural weight, there is no other load

(4) The soil cover of this model is assumed to be a single layer of clay soil, and the indicators are determined according to the reference value of the clay soil

\subsubsection{Loads, Boundary Constraints, and Material Parameters}

(1) Roof Load. Under different burial depths, the pressure load applied to the prefabricated UUT roof by the self-weight of the backfill is

$$
P_{r}=h \cdot \gamma
$$

where $h$ is the thickness of the backfill on the roof and $\gamma$ is the soil heaviness. The model assumes that the backfill is a single layer of cohesive soil. According to the heavy reference value of each clay, $\gamma=18 \mathrm{kN} / \mathrm{m}^{3}$ is proposed.

(2) Side Wall Load.

$$
\begin{aligned}
& P_{u}=\gamma h K, \\
& P_{b}=\gamma(h+H) K,
\end{aligned}
$$

where $P_{u}$ is the lateral Earth pressure on the upper end of the side wall; $P_{b}$ is the lateral Earth pressure at the bottom end of the side wall. $\gamma$ is the soil gravity; $h$ is the thickness of the backfill on the roof. The value of $h$ in this project is between 5.15 and $7.5 \mathrm{~m}$. The model assumes that the backfill is a single layer of cohesive soil. According to the heavy reference value of each clay, $\gamma=18 \mathrm{kN} / \mathrm{m}^{3}$ is proposed; $H$ is the total height of the structure; and $K$ is the static lateral pressure coefficient. According to the reference value of the static side pressure coefficient of the cohesive soil, it is proposed to take $K=0.5$.

(3) Boundary Constraint. The hinged support is designed at both ends of the bottom plate of the tunnel, and the movable hinge support is arranged in the middle of the bottom plate and the longitudinal direction of the tunnel joint. A symmetrical boundary is set at the transverse symmetry plane of the tunnel and the cross section of the bolt rod at the position of the contact surface of the adjacent tunnel.

(4) Material Parameters. The material parameters in the model are shown in Table 1.

\subsubsection{Verification of Simulation Model and Experimental} Results. The measured values of G11 and MH111 and the finite element calculation results at the corresponding positions are shown in Figure 4.

After a comparative analysis, it can be seen that the deformation law of the tunnel obtained by finite element analysis is consistent with the measured deformation law of the tunnel. After the completion of backfilling, the difference between the deformation calculation and the measured at G11 and MH111 is $9.58 \mu \varepsilon$ and $10.84 \mu \varepsilon$, respectively, that is, $26.06 \%$ and $14.87 \%$ of the measured values, respectively. The difference between the numerical calculation result and the measured value is small. This shows that the modelling and material parameters are reasonable, the overall simulation accuracy is high, and the numerical simulation is consistent with the actual monitoring data and the actual situation. The G11 and MH111 strain calculations vary linearly with the increase of backfill thickness. Both have obvious inflection 
TABLE 1: Material parameters

\begin{tabular}{lccc}
\hline Material & Poisson's ratio & Unit weight $\left(\mathrm{kN} / \mathrm{m}^{3}\right)$ & Young's modulus $E(\mathrm{GPa})$ \\
\hline Concrete & 0.2 & 24 & 25 \\
Steel & 0.3 & 70 & 200 \\
\hline
\end{tabular}

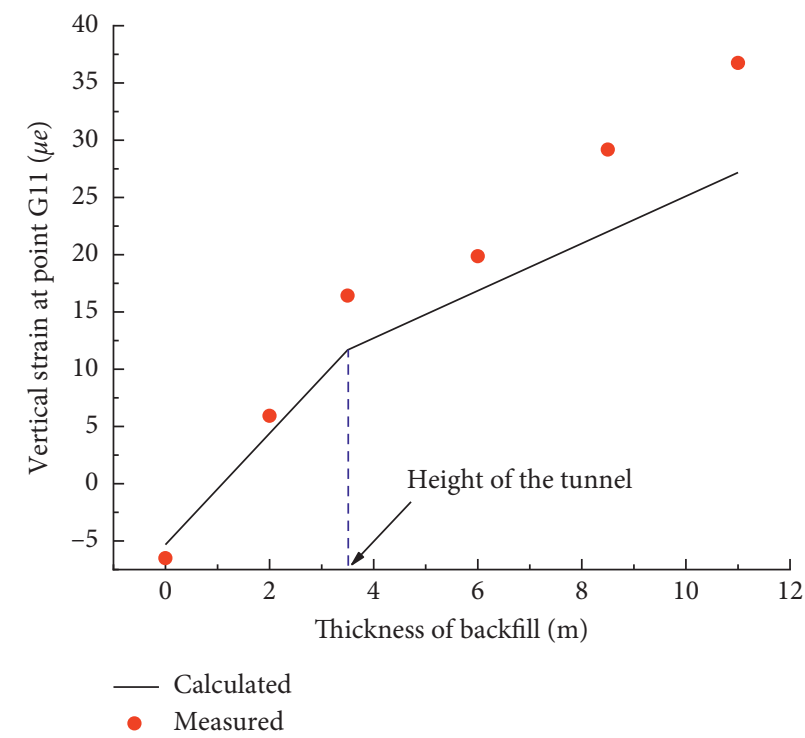

(a)

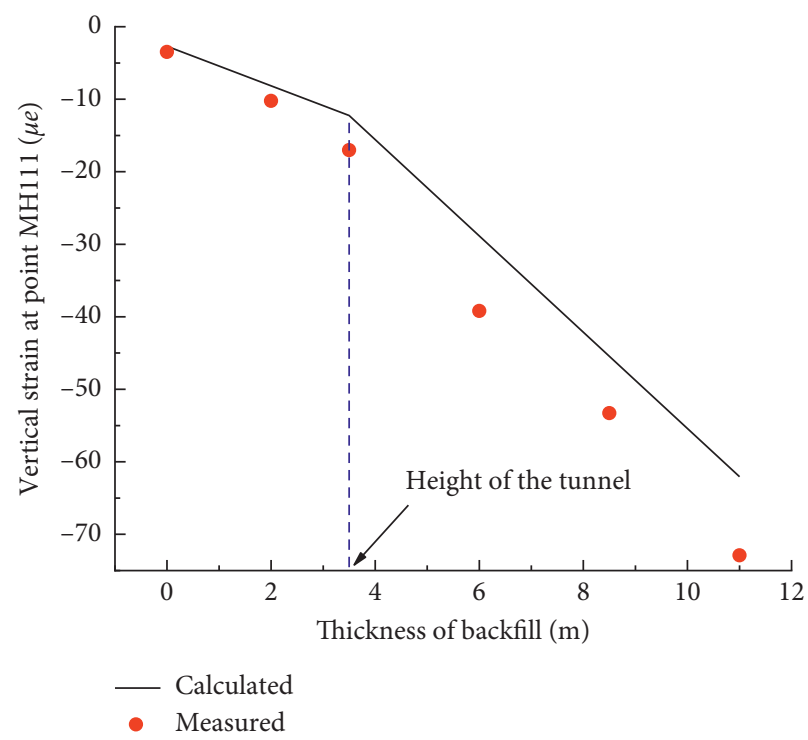

(b)

Figure 4: Comparison between calculated and measured concrete strain: (a) G11 and (b) MH111.

points when the backfill has a thickness of $3.5 \mathrm{~m}$. This is because the height of the tunnel is $3.5 \mathrm{~m}$. When the thickness of the backfill is more than $3.5 \mathrm{~m}$, the roof of the tunnel begins to be stressed. The deformation rate at G11 is reduced, and the deformation rate at MH111 is increased. Due to the limited number of monitoring points, the monitoring results are discrete. The measured deformation is greater than the finite element calculation result. The main reason is that there are different degrees of mechanical disturbance and unbalanced backfilling in the actual construction process, but the influence of mechanical disturbance, unbalanced backfilling, and time-space effect on the deformation of the pipe structure cannot be considered in the simulation process.

\section{Monitoring Results and Discussion}

3.1. Analysis of Concrete Strain Monitoring Data on the Inner Wall of the UUTs. G11, G21, and G31 are the same measuring points of different tunnels, and the working conditions are the same. Therefore, the equivalent strain is calculated by the average of the three values, which is recorded as Gal. Similarly, the equivalent strain calculated from the average of G12, G22, and G32 is recorded as Ga2. The equivalent strain calculated from the average of G13, G23, and G33 is recorded as Ga3. As can be seen from Figure 5(a): The midpoint strain of the side wall of the tunnel is small, and the midpoint strain of the top plate is large. The strain measured when the backfill was completed is greater than the strain measured when the tunnel was installed. The equivalent strain at the midpoint of the side wall increases by about $30 \mu \varepsilon$, and the equivalent strain at the midpoint of the top plate increases by about $75 \mu \varepsilon$.

\subsection{Analysis of Concrete Strain Monitoring Data behind Bolt} Groove. The measured strain can be either positive or negative, but the calculated equivalent strain is all positive. MH111, MH121, MH211, and MH221 are the same measuring points of different tunnels. MH116, MH126, MH216, and MH226 are measuring points symmetric with the previous four points in respect to the vertical central axis of the pipe joint, and the working conditions are the same. The equivalent strain is calculated by the average of the eight values, which is recorded as MHal. Similarly, the equivalent strain of concrete behind the other two bolt slots can be calculated and recorded as $\mathrm{MHa} 2$ and $\mathrm{MHa} 3$, respectively. It can be seen from Figure 5(b) that when the thickness of the backfill is less than $3.5 \mathrm{~m}$, the strain value is relatively small and the change is not large. When the thickness of the backfill is greater than $3.5 \mathrm{~m}$, the strain value increases rapidly. When the thickness of the backfill reaches $11 \mathrm{~m}$, the equivalent strain of $\mathrm{MHa} 2$ is the largest, reaching $174.54 \mu \varepsilon$, and the equivalent strain of MHal is the smallest, which is $89.61 \mu \varepsilon$.

In general, the ultimate compressive strain $\left(\varepsilon_{u}\right)$ of concrete is 0.0033 [18], and the ultimate tensile strain $\left(\varepsilon_{t}\right)$ is 0.0001 . From the monitoring data of this project, the 


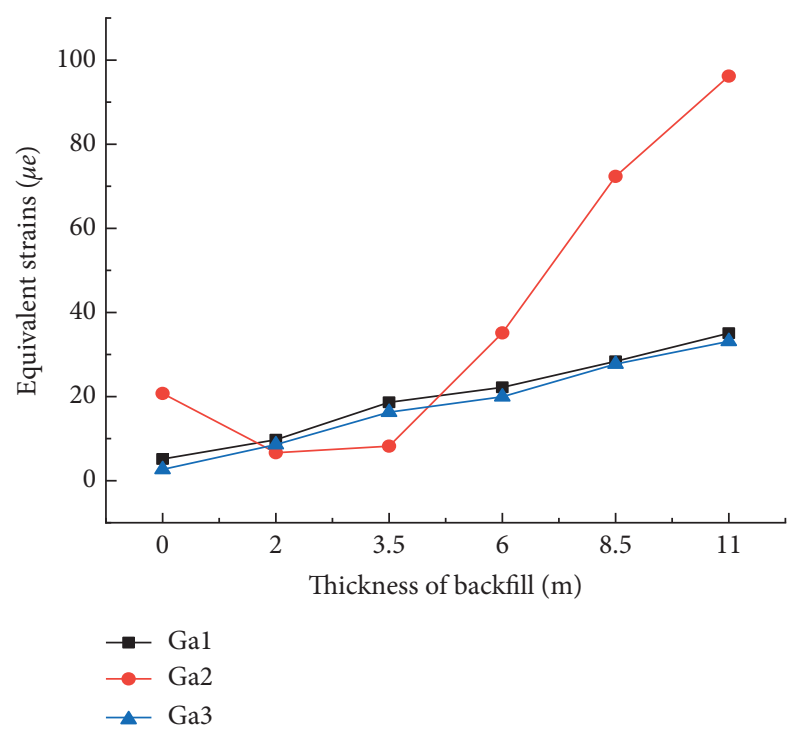

(a)

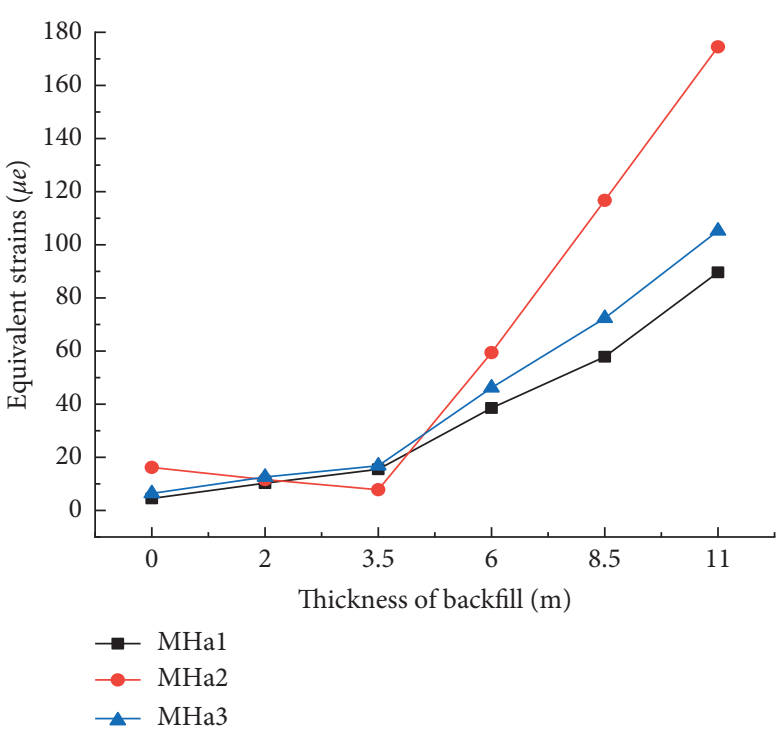

(b)

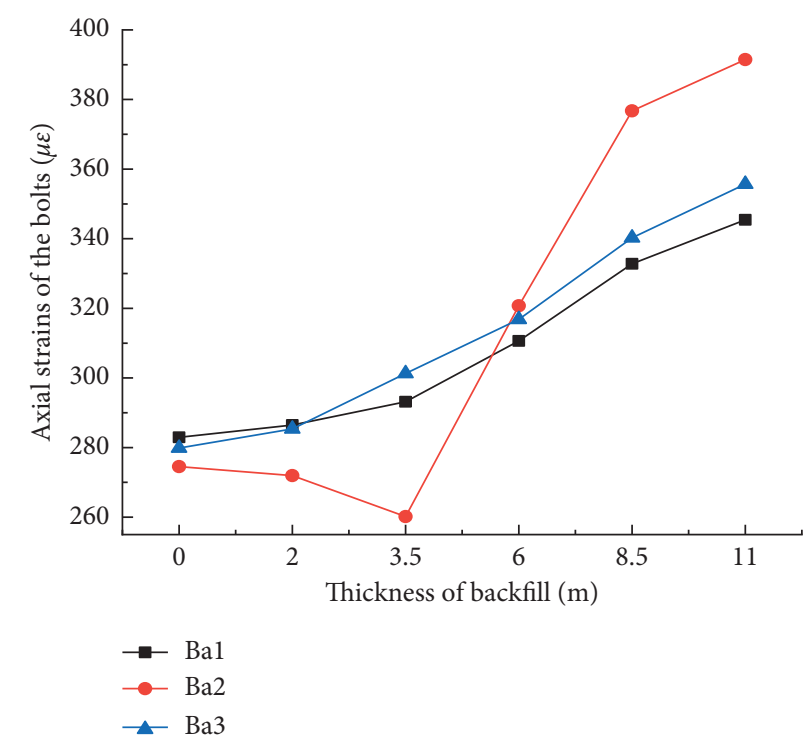

(c)

Figure 5: Statistics of monitoring results. (a) Equivalent strain of concrete at the monitoring point of the tunnel's inner wall. (b) Equivalent strain of concrete at the monitoring point behind the bolt groove. (c) Strain of connecting bolts between tube joints.

concrete strain of the UUT did not exceed the limit value, and the work performance was good.

3.3. Analysis of Strain Monitoring Data of Connecting Bolts. B11 and B21 are the same measuring points of different tube joints. B16 and B26 are measuring points symmetric with the previous 2 points in respect to the vertical central axis of the pipe joint and the working conditions are the same. The strain is calculated by the average of the four values, which is recorded as $\mathrm{Ba} 1$. And so, the strain of the other two bolts can be calculated and recorded as $\mathrm{Ba} 2$ and $\mathrm{Ba} 3$, respectively. It can be seen from Figure 5(c) that after the tunnel installation was completed, the axial strain values of the bolts at the three monitoring points were similar when the backfilling operation was not performed, which was about $280 \mu \varepsilon$. As the thickness of the backfill increases, the values of $\mathrm{Ba} 1$ and $\mathrm{Ba} 3$ increase in the same trend. By the time the backfill is completed, the maximum value of $\mathrm{Ba} 1$ and $\mathrm{Ba} 3$ is reached, approximately $345 \mu \varepsilon$ and $355 \mu \varepsilon$, respectively. When the thickness of the backfill is less than $3.5 \mathrm{~m}$, the value of $\mathrm{Ba} 2$ is slowly decreasing. However, after the thickness of the backfill is more than $3.5 \mathrm{~m}$, which is after the filling of the top of the roof, the value of $\mathrm{Ba} 2$ increases rapidly. By the time the backfill is completed, the maximum value is reached, which is approximately $392 \mu \varepsilon$.

The bolt strength grade of this project is 8.8 , the nominal yield strength of the bolt material is $640 \mathrm{MPa}$, and the yield strain is $3200 \mu \varepsilon$. From the monitoring data of this project, the bolt strain is far less than the limit value, and the working performance is good. 


\section{Numerical Simulation Results and Discussion}

4.1. Model Deformation Analysis. The structural deformation analysis of the model was carried out by the finite element analysis software COMSOL. It can be seen from the deformation characteristics of the model structure that the deformation of the roof and the side wall of the model is significant. It also can be seen from the maximum principal strain of the model that the middle part of the roof, the corners, and the upper end of the side wall are dangerous areas of stress concentration. Therefore, this paper mainly analyzes the stress distribution at these positions of the roof and the side wall.

4.1.1. Vertical Displacement Analysis of the Roof. With the finite element software COMSOL, we added a line in the middle of the cross section of the roof in the calculation result data set. We extracted the vertical displacement of the line and drew its vertical displacement curve, as shown in Figure 6(a). The positive sign in the figure indicates that the roof is convex upward, and the negative sign indicates that the roof is concave downward. $0 \mathrm{~m}, 3.5 \mathrm{~m}, 8.65 \mathrm{~m}$, and $11 \mathrm{~m}$ in the legend, respectively, indicate the thickness of the backfill. It can be seen from the vertical displacement curve that when the thickness of the backfill is smaller than the height of the tunnel, the vertical displacement of the roof is small. After the thickness of the backfill is greater than the height of the tunnel $(3.5 \mathrm{~m})$, the roof begins to bear the load and the vertical displacement increases rapidly. The deformation of the roof is approximately parabolic, starting from the middle to the inner concave. The middle vertical displacement is the largest, and the vertical displacement of the two ends is the smallest. As the thickness of the backfill increases, the vertical displacement of the roof is gradually increased. Moreover, the amount of vertical displacement change in the middle portion is much larger than that at both ends. It indicates that the middle part of the roof is sensitive to the thickness of the backfill or the vertical load of the roof (Figure 6(a)).

4.1.2. Side Wall Deformation Analysis. In the same way, a line was made from bottom to top in the middle of the side wall. We extracted the lateral displacement of the line and plotted its lateral displacement curve, as shown in Figure 6(b). The positive sign in the figure indicates that the side wall plate is convex outward, and the negative sign indicates that the side wall plate is concave inward. The legend showed the same as above. As can be seen from Figure 6(b), the side wall deformation is approximately wavy. The middle inward concave part is most obviously deformed, and the displacement is the largest. Some of the side wall plates are convex outward at the upper end $3 \mathrm{~m}$, and the lower end displacement is the smallest. As the thickness of the backfill increases, the displacement in the middle of the side wall increases rapidly, and the maximum inward concave is about $0.17 \mathrm{~mm}$. This phenomenon is consistent with the experimental results of the prototype of the tunnel obtained by Xue Weichen et al.

\subsection{Model Stress Analysis}

4.2.1. Stress Analysis of Roof Concrete. According to the mesh division, the concrete unit on the outer side (uppermost layer) of the roof and the concrete unit on the inner side (lowermost layer) of the roof are taken as research objects. The stresses of the concrete inside and outside the middle position of the prefabricated UUT were extracted separately, and the stress changes under different backfill soil thicknesses were analyzed.

(1) Stress Analysis of the Outer Side (Uppermost Layer) of the Roof. Stress concentration occurs in three areas of the outer (uppermost) concrete of the roof under surrounding soil pressure loading, as shown in Figure 7. Among them, the $A$ area is mainly tensile stress, and the $D$ area (middle area) is mainly composed of compressive stress. As the thickness of the backfill increases, the stress on the outer (uppermost) layer of the roof increases gradually, and the stress in the stress concentration area increases significantly, as shown in Figures 8(a) and 8(b).

Prediction of the concrete failure mode on the outer side of the roof: with the increase of the thickness of the backfill, the concrete in the A area outside the roof is cracked, and the concrete in the $D$ area is squeezed. Groundwater penetration may be caused by concrete cracking in area $A$.

(2) Stress Analysis of Concrete inside the Roof. Stress concentration occurs at the corners ( $E$ area) and the middle $(B$ area) of the inner side of the roof concrete under the surrounding Earth pressure load, as shown in Figure 7. The end corner area is mainly composed of compressive stress, and the middle part is mainly tensile stress. The tensile stress in zone $\mathrm{B}$ is greater than the tensile stress in zone A. As the backfill thickness increases, the stress in the central region and the corners at both ends increases significantly, and the stress in the central region increases faster than the corner region, as shown in Figures 8(c) and 8(d).

Prediction of concrete failure on the inside (lowest layer) of the roof: as the thickness of the backfill increases, the concrete in the middle of the inside of the roof cracks and gradually extends to both sides. The concrete in the corner area is crushed and destroyed.

\subsubsection{Stress Analysis of Concrete for Side Wall}

(1) Stress Analysis of the Outer Side of the Side Wall. Using the same method, the concrete of the side wall of the model is divided into the outer side and the inner side, and the stress distribution is analyzed separately. Two stress concentration areas appear on the concrete outside the side wall panels: $\mathrm{C}$ and $\mathrm{F}$ areas, as shown in Figure 7 . From bottom to top, we extract the stress value of the middle unit on the outer side of the side wall and draw the stress curve, as shown in Figures 9(a) and 9(b). 


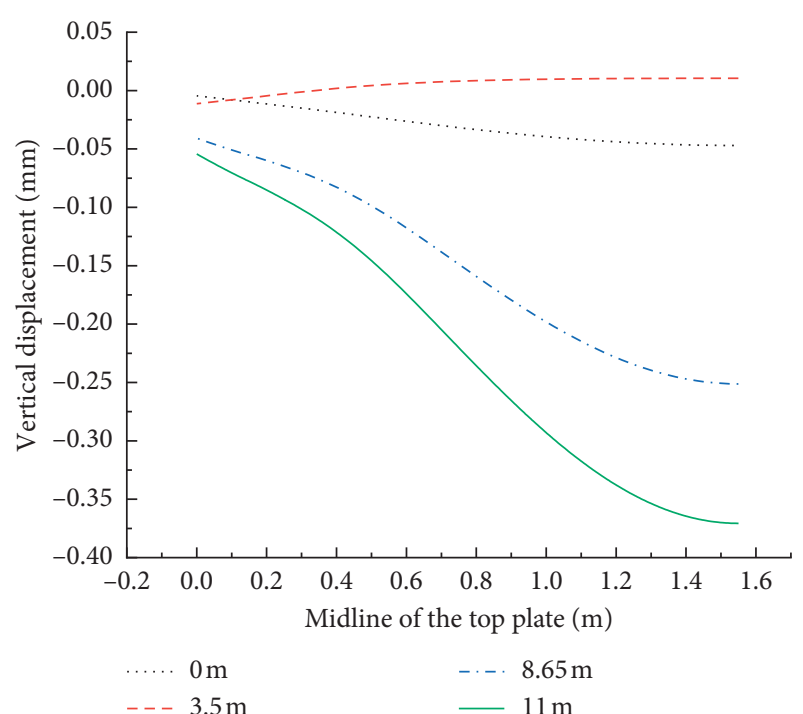

(a)

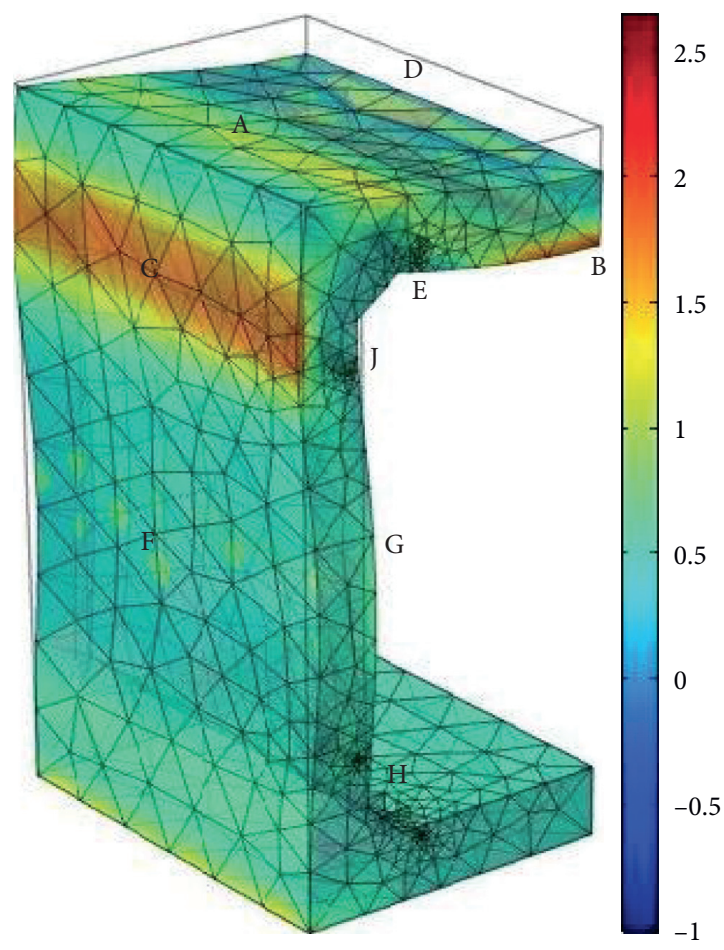

(a)

Figure 7: Principal stress cloud of the model. (a) First principal stress. (b) Third principal stress.

Figure 6: Displacement curve. (a) The top plate. (b) The side wall.

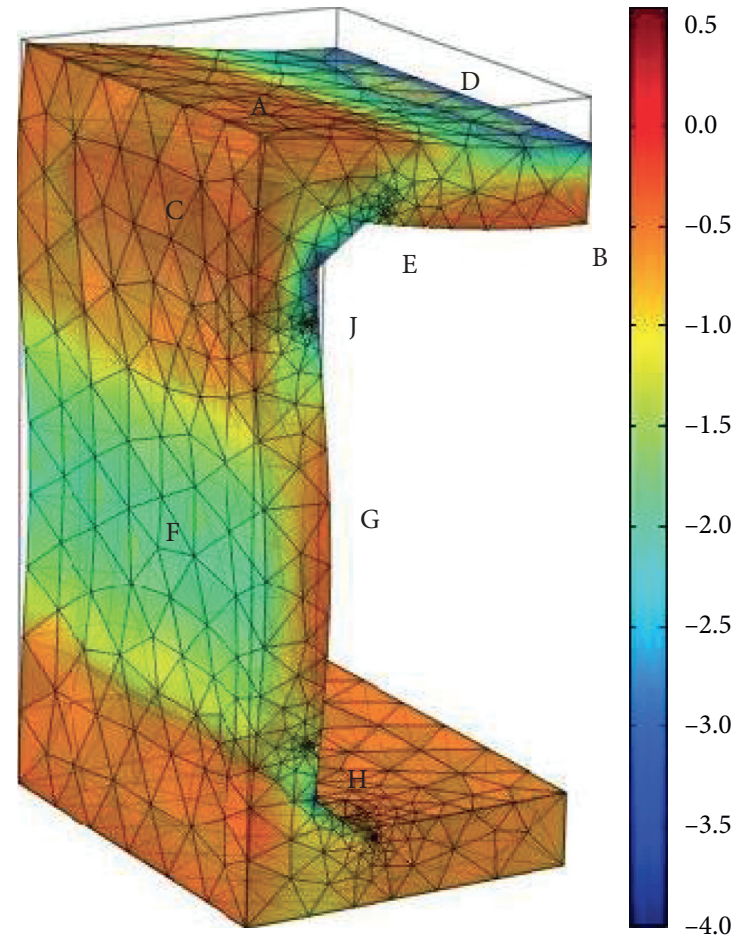

(b)

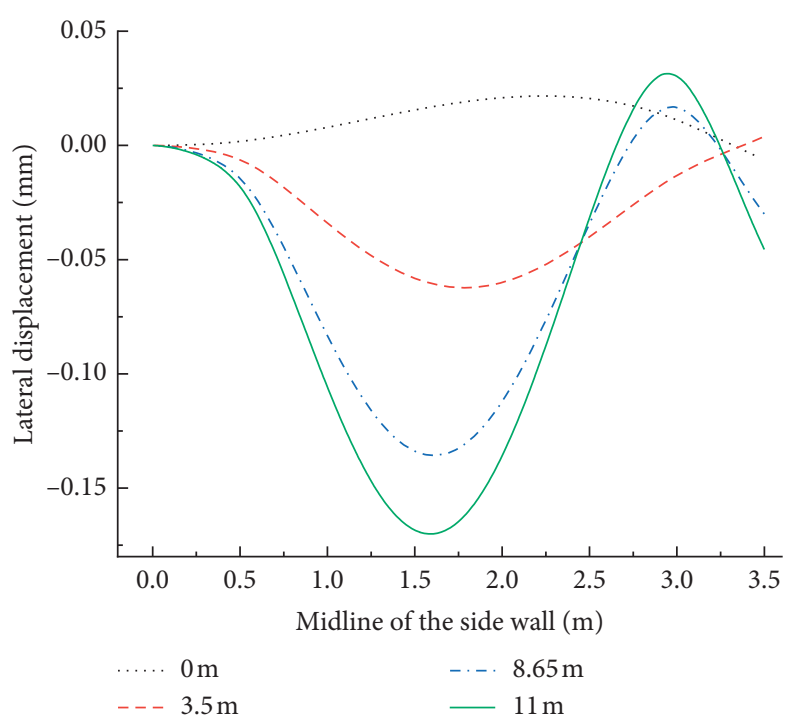

(b)
It can be seen from Figures 9(a) and 9(b) that, as the thickness of the backfill increases, the stress also begins to increase gradually, and the stress growth rate in the $\mathrm{C}$ region and the $\mathrm{F}$ region is faster. The $\mathrm{C}$ region is mainly dominated by tensile stress, and the $\mathrm{F}$ region is mainly dominated by compressive stress.
Prediction of concrete failure on the outside of the side wall: with the increase of the thickness of the backfill, the concrete in the $\mathrm{C}$ area outside the side wall plate begins to bulge outward, and cracking occurs, which causes the groundwater to penetrate from the concrete crack in the $\mathrm{C}$ area to the inside of the tunnel structure. 


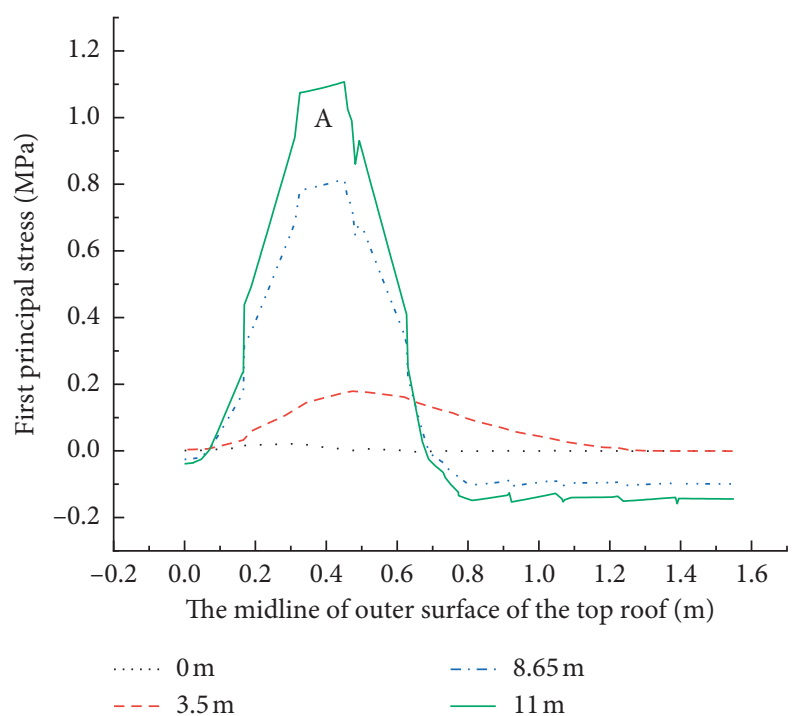

(a)

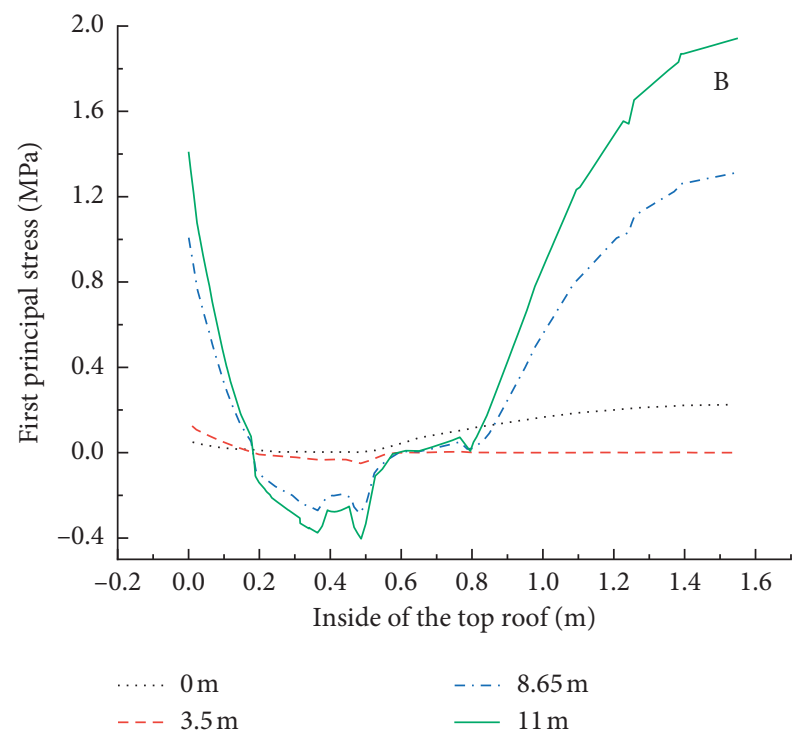

(c)

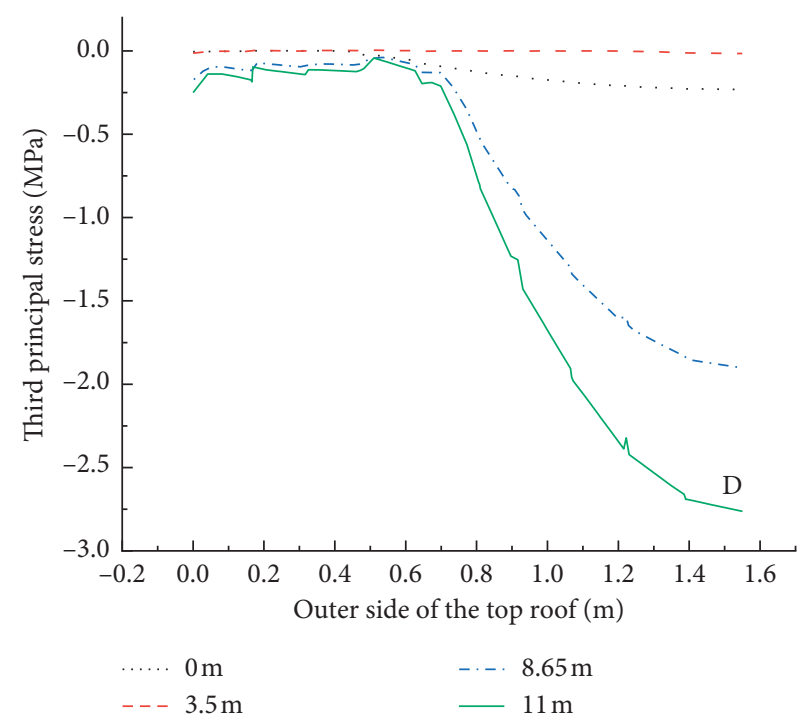

(b)

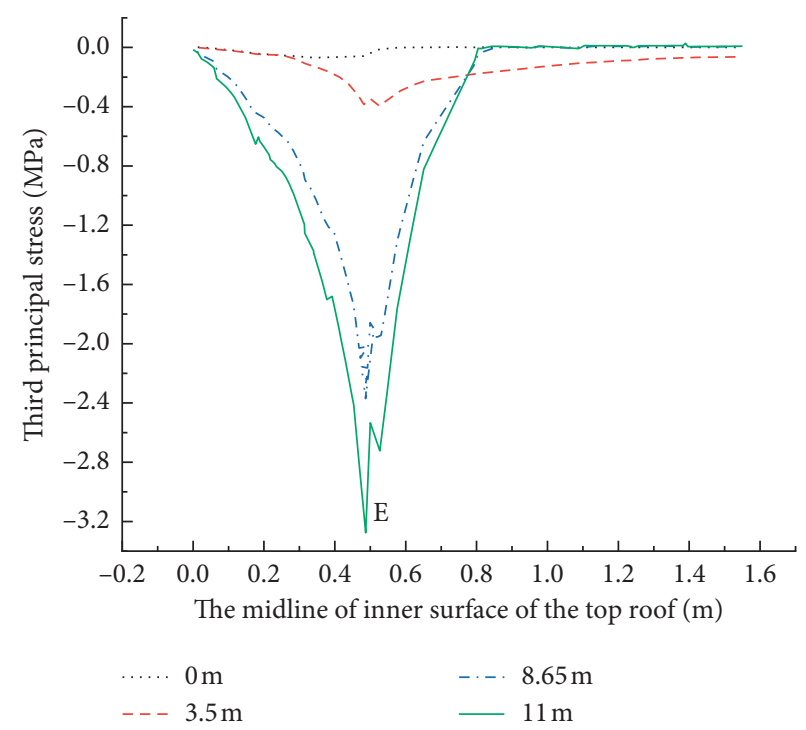

(d)

Figure 8: Principal stress variation curve of concrete on the midline of the roof. (a) First principal stress on the outer surface of the roof. (b) Third principal stress on the outer surface of the roof. (c) First principal stress on the inner surface of the roof. (d) Third principal stress on the inner surface of the roof.

(2) Stress Analysis of the Inner Side of the Side Wall. It can be seen from Figures 9(c) and 9(d) that the concrete stress in the upper corner of the inner side wall of the side wall plate is highly concentrated and then slowly decreases downward, and the stress is slightly increased in the low-end corner region. As the thickness of the backfill increases, the concrete stress in the upper corner region increases significantly, mainly due to compressive stress.

Prediction of concrete failure on the inside of the side wall: as the thickness of the backfill increases, the concrete stress in the upper corner of the structure increases sharply, which may cause the concrete in the corner of the side wall to be crushed and eventually cause crushing damage.
4.2.3. Stress Analysis of Connecting Bolts. The position and number of the connecting bolts of the prefabricated UUT are shown in Figure 10(a). We named the bolts from bottom to top in order of bolt 1 , bolt 2 , bolt 3 , and bolt 4 . Figure 10(a) shows the stresses of the bolts and spacers when the backfill has a thickness of $8.65 \mathrm{~m}$. It can be seen from the figure that the bolt rod is subjected to tensile force, the bolt head is subjected to pressure, and the contact stress of the gasket is relatively uniform. With the finite element software COMSOL, we extracted the axial tension of the bolt in the calculation result data set. We have drawn the axial force of the bolts along with the thickness of the backfill, as shown in Figure 10(b). 


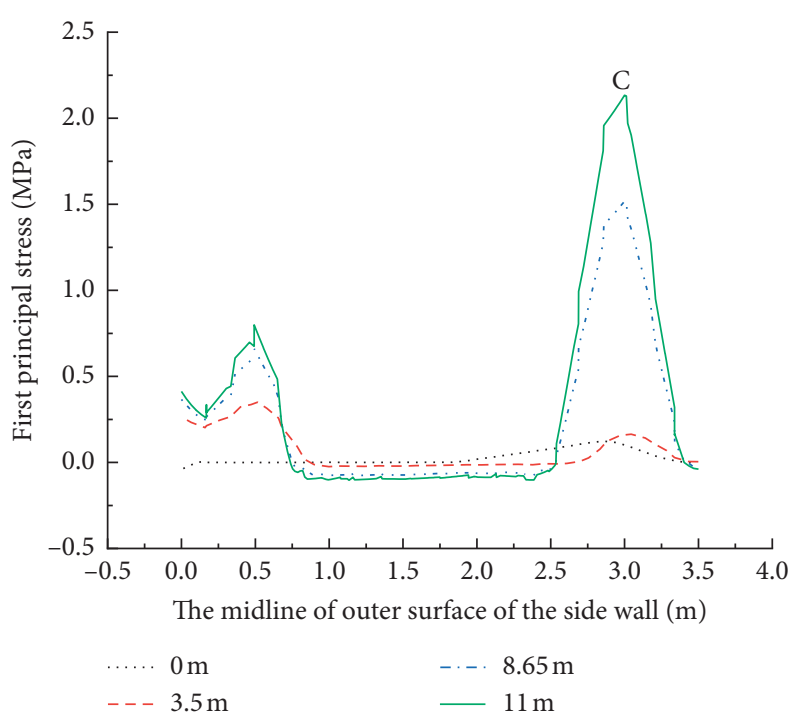

(a)

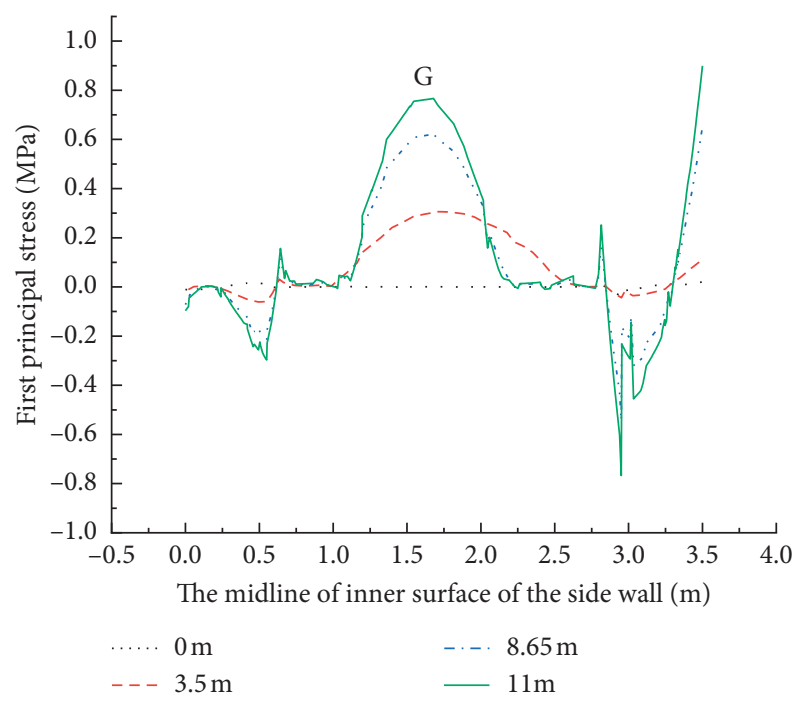

(c)

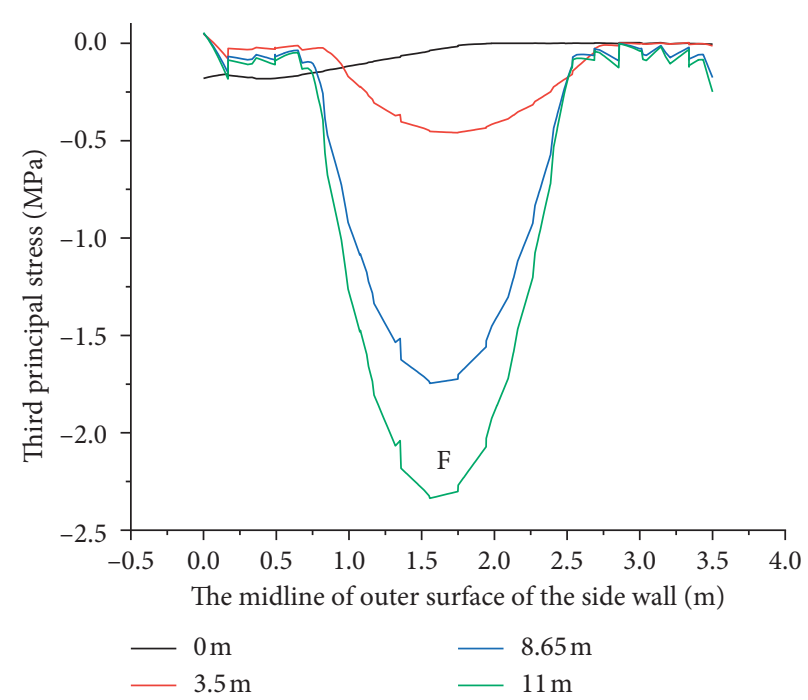

(b)

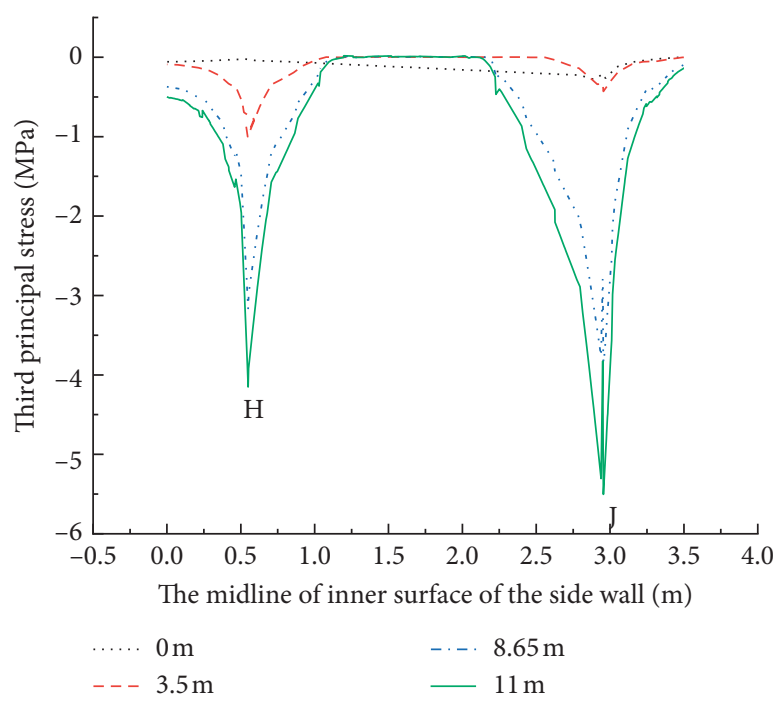

(d)

FIgURE 9: Main stress variation curve of concrete on the midline of the side wall. (a) First principal stress on the outer surface. (b) Third principal stress on the outer surface. (c) First principal stress on the inner surface. (d) Third principal stress on the inner surface.

It can be seen from the figure that the inflection point occurs when the thickness of the backfill reaches $3.5 \mathrm{~m}$ (the height of the UUT). Before this, as the thickness of the backfill increases, the axial tensile force of bolt 1 , bolt 2 , and bolt 4 increases continuously. Bolt 4 has the fastest increase in tensile force, with a maximum increase of approximately $0.1 \mathrm{kN}$. The axial tension of bolt 3 is continuously reduced. After that, the axial tension of the four bolts increased continuously. The axial tensile force of bolt 3 increases the fastest, with a maximum increase of approximately $0.8 \mathrm{kN}$. In general, the bolt axial force is not increased much, and the bolts work well.

4.2.4. Stress Analysis during the Operation Period. During the operation of the tunnel, the vehicle load is its main load, which is a dynamic load. Backfill and pavement surface layer will buffer and diffuse the dynamic load of the vehicle. When the thickness of the top cover is large, the influence of the wheel load on the dynamic force of the roof is not obvious. When the thickness of the covering soil is greater than or equal to $0.7 \mathrm{~m}$, we can take a dynamic coefficient of 1.0. Because the thickness of the roof of the tunnel roof of the project is much larger than $0.7 \mathrm{~m}$, we did not carry out a dynamic analysis calculation. Referring to the "Urban Bridge Design Load Standard," we used the city-A class vehicle load and lane load value and converted it into a uniform load (about $32 \mathrm{kN} / \mathrm{m}^{2}$ ), which was applied directly above the outer side of the roof of the tunnel.

According to the stress analysis of the tunnel concrete, the maximum value of the compressive stress is located inside of the side wall. We compared the minimum principal stresses for both operating and backfilling conditions, as shown in Figure 11(a). After the completion of the backfilling, the maximum value is $5.5 \mathrm{MPa}$, while the maximum 


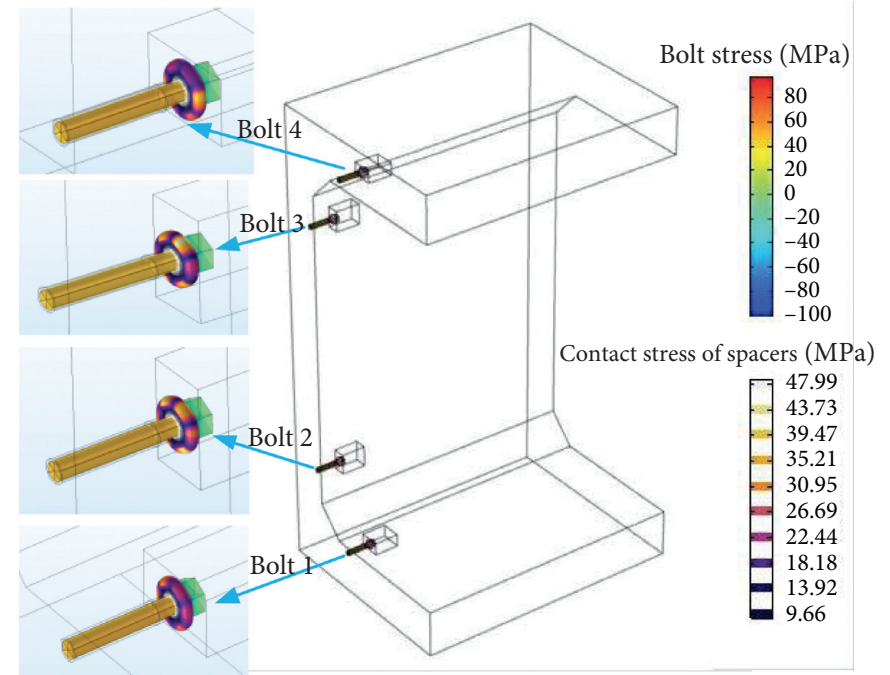

(a)

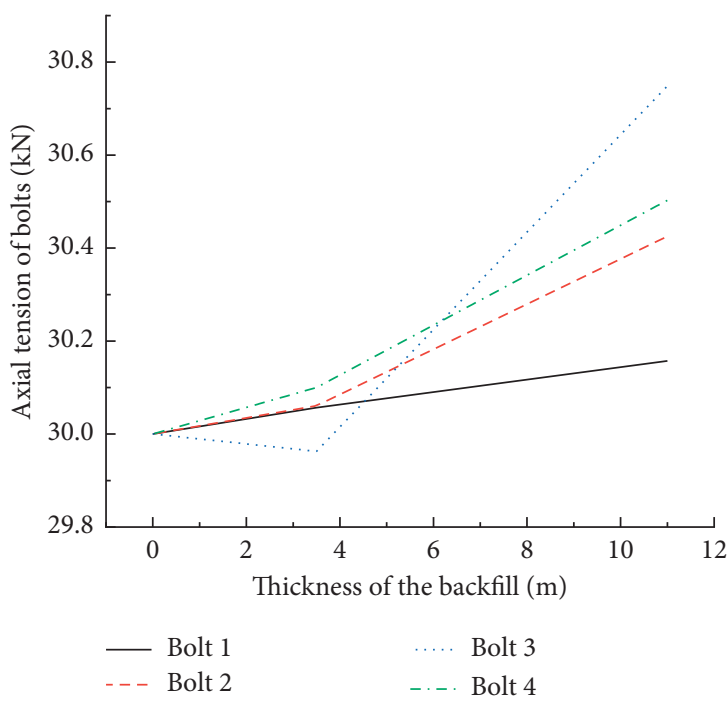

(b)

FiguRE 10: Stress of bolts after backfilling. (a) The number and location of the bolts. (b) Curve of axial force of bolts with backfill soil thickness.

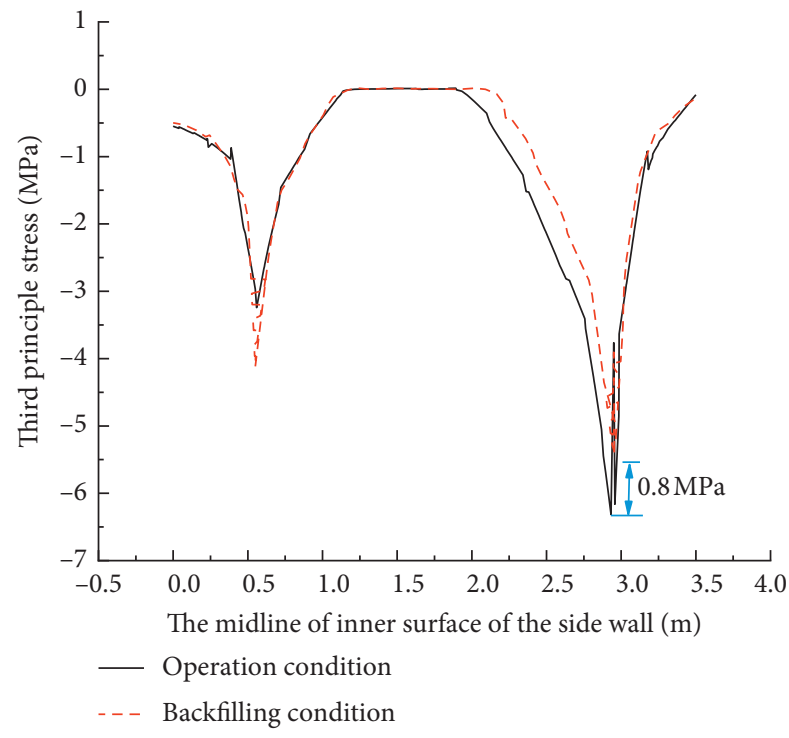

(a)

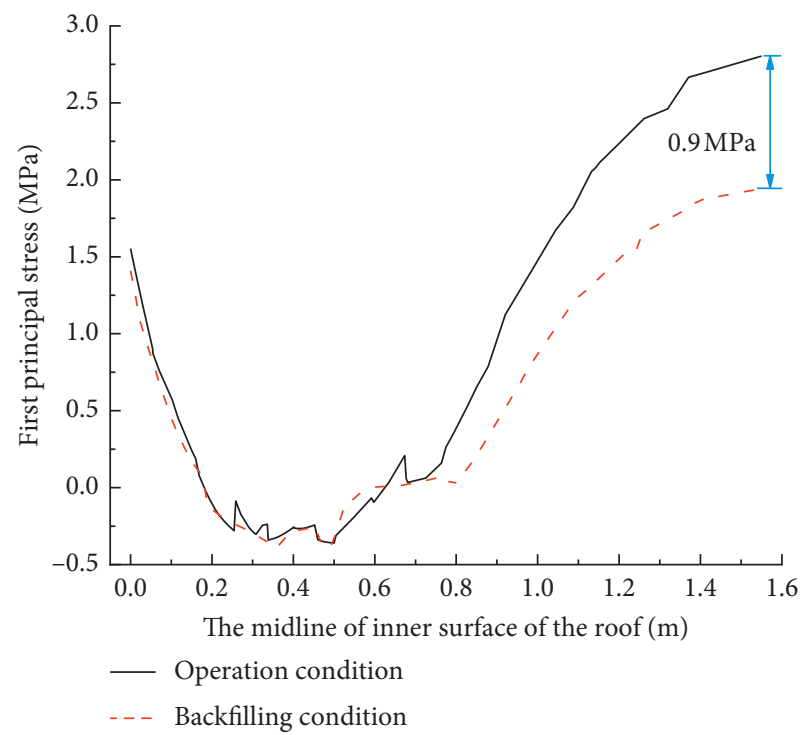

(b)

FIGURE 11: Continued. 


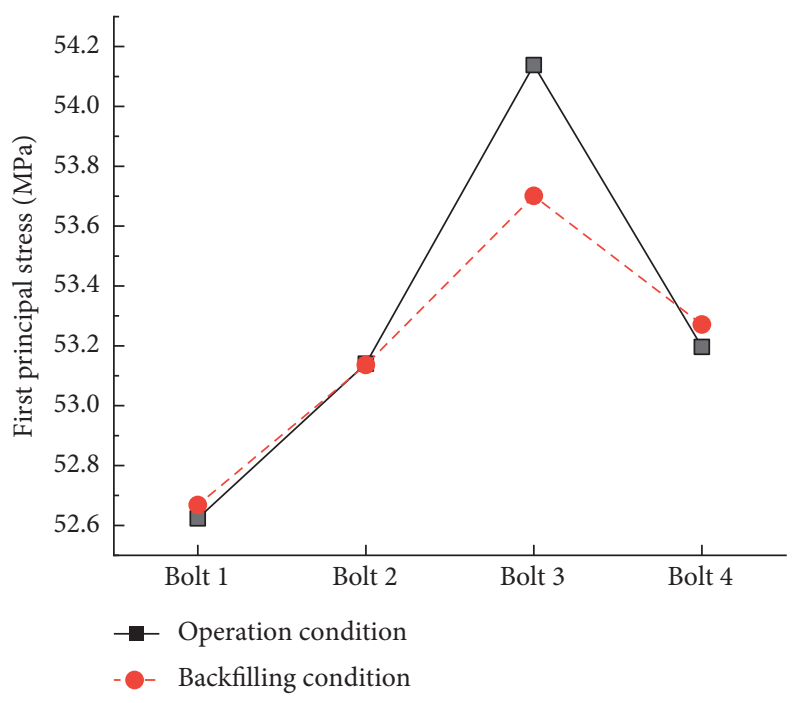

(c)

Figure 11: Comparison of operation and backfilling conditions. (a) Third principal stress of concrete on the inner surface of side wall. (b) First principal stress of concrete on the inner surface of the roof. (c) Maximum stress of connecting bolts.

value during operation is $6.3 \mathrm{MPa}$, and the maximum compressive stress is increased by $0.8 \mathrm{MPa}$. The position where the maximum value is located has not changed, and it is located in the $E$ area concrete inside the side wall panel. The tensile stress maximum is located on the inside of the roof. We compared the maximum principal stresses under both operating and backfill conditions, as shown in Figure 11(b). After the completion of the backfilling, the maximum value is $1.9 \mathrm{MPa}$, while the maximum value during operation is $2.8 \mathrm{MPa}$, and the tensile stress is increased by $0.9 \mathrm{MPa}$. There is no change in the position of the maximum value under the operating conditions, and it is still located in the B area concrete inside of the roof.

We compared the maximum principal stress of the connecting bolts under the two conditions of operation and backfilling, as shown in Figure 11(c). The change of maximum principal stress of bolt 1 , bolt 2 , and bolt 4 is small, and the maximum principal stress of bolt 3 is significantly increased from $53.70 \mathrm{MPa}$ to $54.14 \mathrm{MPa}$, an increase of $0.44 \mathrm{MPa}$. Since the strength of the connecting bolts is 8.8 (the yield strength is about $640 \mathrm{MPa}$ ), the maximum principal stress of the bolts is much smaller than the yield strength. Therefore, the working performance of the bolts under operating conditions is good.

\section{Conclusions}

Through the monitoring of the installation and backfilling of the tunnel, the strain variation law of the concrete and bolts of the UUT was obtained. Both deformations were less than the ultimate strain. The concrete on the inner wall of the tunnel and bolts work well under the two conditions of installation and backfilling. The rationality of the numerical model of the prefabricated tunnel was verified by on-site monitoring results. The following conclusions can be drawn from this study:
(1) The structural stress redistribution occurs in the prefabricated UUT under the upper layer of soil loading. The $\mathrm{A}$ area and $\mathrm{C}$ outside the tunnel are prone to cracking of the surface concrete, which may cause groundwater penetration. The design should consider and take appropriate precautions.

(2) As the thickness of the backfill of the tunnel increases, the axial tension of the four bolts increases continuously, and the tensile force of bolt 3 increases the fastest. Compared with the installation condition, the axial force of the bolts in the backfilling condition does not increase much, and the maximum principal stress is much less than its yield strength.

(3) Through the stress analysis of the concrete and bolts under the operating conditions, it is expected that the concrete and bolts of the UUT will work well.

(4) The influence of the thickness of the backfill on the prefabricated UUT is significant. The unreasonable backfill thickness will cause concrete cracking and heavy structural damage. It is essential to check the backfill thickness of prefabricated UUT in the design process.

Despite the increasing popularity of prefabricated UUT, the application of prefabricated UUT connected by bolts is not particularly extensive, and many problems remain to be further studied. The model in this paper does not consider the seismic action. The next step is to apply a seismic load to the model to study the dynamic response of the prefabricated UUT structure and bolt connection. With the prolonged use of prefabricated UUT, the groundwater may change. Therefore, the impact of changes in groundwater level on structure and connection performance should also be taken into account. 


\section{Data Availability}

The data used to support the findings of this study are included within the article.

\section{Conflicts of Interest}

The authors declare that they have no conflicts of interest regarding the publication of this paper.

\section{Acknowledgments}

The authors are very grateful for the funding support from the Key Technology Research of Beijing Urban Underground Space Engineering (Grant no. FRF-BD-18-007A) and the Construction of Key Disciplines in Beijing.

\section{References}

[1] J.-V. Valdenebro and F. N. Gimena, "Urban utility tunnels as a long-term solution for the sustainable revitalization of historic centres: the case study of Pamplona-Spain," Tunnelling and Underground Space Technology, vol. 81, pp. 228-236, 2018.

[2] J. Canto-Perello and J. Curiel-Esparza, "Assessing governance issues of urban utility tunnels," Tunnelling and Underground Space Technology, vol. 33, pp. 82-87, 2013.

[3] T. Wang, L. Tan, S. Xie, and B. Ma, "Development and applications of common utility tunnels in China," Tunnelling and Underground Space Technology, vol. 76, pp. 92-106, 2018.

[4] J. Canto-Perello and J. Curiel-Esparza, "An analysis of utility tunnel viability in urban areas," Civil Engineering and Environmental Systems, vol. 23, no. 1, pp. 11-19, 2006.

[5] Shanghai Municipal Engineering Design and Research Institute (Group) Co Ltd Tongji University, China Urban Planning and Design Institute, Shanghai Construction Engineering Group Co Ltd et al., Technical Specification for Urban Utility Tunnel Engineering, GB 50838-2012, Shanghai Jiaotong University, Shanghai, China, 2012, in Chinese.

[6] S.-H. Wang, A. Jierula, P.-Y. Wang, and W.-H. Liu, "Mechanics performance analysis of precast rectangle box culvert and damage prediction of key parts," Journal of Northeastern University, vol. 39, no. 2, pp. 260-265, 2018, in Chinese.

[7] J. Chen, L. Jiang, J. Li, and X. Shi, "Numerical simulation of shaking table test on utility tunnel under non-uniform earthquake excitation," Tunnelling and Underground Space Technology, vol. 30, pp. 205-216, 2012.

[8] A. K. Garg and A. Abolmaali, "Finite-element modeling and analysis of reinforced concrete box culverts," Journal of Transportation Engineering, vol. 135, no. 3, pp. 121-128, 2009.

[9] A. K. Garg, A. Abolmaali, and R. Fernandez, "Experimental investigation of shear capacity of precast reinforced concrete box culverts," Journal of Bridge Engineering, vol. 12, no. 4, pp. 511-517, 2007.

[10] X. Hu and W. Xue, "Experimental study of mechanical properties of PPMT," China Civil Engineering Journal, vol. 43, no. 5, pp. 29-37, 2010, in Chinese.

[11] W. Xue, X. Hu, and H. Wang, "Experimental studies on mechanical properties of PPMT in Shanghai Expo area," Special Structures, vol. 26, no. 1, pp. 105-108, 2009, in Chinese.

[12] X. Hu, W. Xue, H. Wang, and L. Sun, "Construction monitoring and analysis of PPMT in Shanghai Expo area," Special Structures, vol. 26, no. 2, pp. 105-108, 2009, in Chinese.
[13] X. Du, H. Liu, D. Lu, C. Xu, F. Luo, and S. Li, "Study on seismic performance of sidewall joints in assembled monolithic subway station," China Civil Engineering Journal, vol. 50, no. 4, pp. 38-47, 2017, in Chinese.

[14] K. Wang, C. Zhang, and M. Zhang, "Study of strain measurement and data processing methods," Journal of Dalian Jiaotong University, vol. 40, no. 2, pp. 80-83, 2019, in Chinese.

[15] H. Xianjie, W. Yingnan, and K. Yang, "Anisotropy of crack initiation strength and damage strength of coal reservoirs," Petroleum Exploration and Development, vol. 48, no. 1, pp. 1-12, 2021.

[16] X. Hao, W. Du, Y. Zhao et al., "Dynamic tensile behaviour and crack propagation of coal under coupled static-dynamic loading," International Journal of Mining Science and Technology, vol. 30, no. 5, pp. 659-668, 2020.

[17] Z. Song, Y. Wang, H. Konietzky, and X. Cai, "Mechanical behavior of marble exposed to freeze-thaw-fatigue loading," International Journal of Rock Mechanics and Mining Sciences, vol. 138, Article ID 104648, 2021.

[18] Ministry of Housing Urban Rural Development China, Code for Design of Concrete Structures, GB 50010-2010, Ministry of Housing Urban Rural Development China, Beijing, China, 2010, in Chinese. 